\title{
Efficacy of Stress Management Program on the level of perceived stress and Coping Strategies among Baccalaureate Nursing Students
}

\author{
Samar Mabrook El-Nehrawaya: Lecturers of Psychiatric and Mental Health Nursing, \\ Faculty of Nursing, Tanta University
}

Souzan Abd El-Menem: Lecturers of Psychiatric and Mental Health Nursing, Faculty of Nursing, Tanta University

\begin{abstract}
Background: Undergraduate nursing students experience significant stress and anxiety, stress has been known as a barrier to concentration, problem solving, decision making, and other important abilities for students' learning. The Ways of coping with such stress would be more important than the nature of stress itself. Aim: the aim of this study was to evaluate the efficacy of stress management program on the level of perceived stress and coping strategies among Baccalaureate Nursing Students. Subject and method: A quasi-experimental with one group pre-test post-test design was selected for the study. A convenience sampling of 100 nursing students at academic year (2017-2018). The study was conducted at faculty of nursing, Tanta University affiliated to the Ministry of Higher Education. Tools of data collection ; three tools were used to collect the data for the study ;University student's perceived stressors questionnaire, Coping inventory of stressful situations and Perceived stress scale Method: The nursing students were divided into subgroups; each subgroup encompassed 15 students (8 students for each researcher). Each subgroup was attending a total of 6 sessions. These sessions were scheduled as 3 sessions per week for duration of 2 weeks. Each session was lasted for about two hours. Results: More than half of the study participants were classified as having a high level of stress and the most used coping strategies were emotion focused and avoidance focused strategy before implementing the program. There was a statistical significant difference in the level of stress and coping strategies used by nursing students among the two phases of the program. Conclusion: The program was effective in reducing stress level and improves coping strategies.
\end{abstract}

Key words: Nursing students, Stress management Program, Coping strategies, perceived stress. 


\section{Introduction}

Nursing is a challenging profession with persistent levels of stress that lead to high attrition rates observed among newly graduated nurses; attrition that adversely influences patient care and increases costs (1). Stress is experienced when an individual perceives their available resources are insufficient to adapt to a situation ${ }^{(2)}$.Stress is defined as a transaction that occurs between a person and his/her environment that exceeds his/her internal resources, endangers his/her well-being, and burdens his/her coping resources ${ }^{(3)}$.Any event or any stimulus that cause an individual to experience stress is called a stressor ${ }^{(4)}$.

A nursing student is exposed to several stressors such as academic demands, unfamiliar clinical situations like exam, assignment, as well as to personal stressors like demands of families, jobs, or sports, which interfere with the demands of fulltime education ${ }^{(5)}$. In fact, Personal demands exacerbate stress as many students hold full- or part-time jobs while in nursing college due to financial constrains ${ }^{(\mathbf{1 , 6})}$. Moreover, financial strain and limited leisure time may negatively influence availability and access to sources of social support ${ }^{(5)}$. All the previously mentioned stressors are negatively impacts students' physical and mental health and hinders academic performance and achievement rates ${ }^{(7-9)}$.

The widespread prevalence of stress among nursing students arise the need for coping. The amount of stress experienced by nursing students depending on the individual's capability to successfully cope with stressful events and situations ${ }^{(\mathbf{1 0})}$.The concept of coping is multi-faceted ${ }^{(\mathbf{1 1})}$.Many definitions exist for the construct of coping but most of them include similar concepts. Compas et al(2001) who define coping as "conscious efforts to control, thought, behavior, physiology, emotion and the environment in response to stressful events $^{(\mathbf{1 2})}$. To date, the most widely accepted and influential definition of coping is grounded in Folkman and Lazarus (1980)who defies coping as "the cognitive and behavioral efforts to manage specific external and/or internal demands evaluated as exceeding the resources of the individual $^{(13)}$. A characteristic of this conception is that coping is not a trait, but rather a constantly changing state that evolves according to the current demands of the individual's relationship with his her environment $^{(\mathbf{1 4})}$.

Coping strategies are classified into three categories: problem -oriented (strategies to actively solve an underlying problem, and 
potentially decrease its adverse effects), emotion-oriented (i.e. strategies to reform cognitions in order to modify the emotional reaction), and avoidanceoriented (e.g. "giving up", denial, or engaging in another task, choosing to be with other people and seeking emotional support) ${ }^{(15)}$.

Nursing students who utilized maladaptive coping strategies such as avoidance or transference strategies perceived more stress than those who utilized problem focused coping strategies ${ }^{(16)}$.Unfortunately, Stress is handled by nursing students at many times by adverse techniques like substance abuse or by self -blaming ${ }^{(\mathbf{1 7 - 1 8})}$.If nursing students failed to effectively cope with sustained stress it can be internalized and negatively influence the health of the nursing students themselves and total wellbeing, holistic patient care, and professionalism in nursing; these can then become obstacles to optimal learning and nursing performance ${ }^{(2,5)}$. Therefore, development of a stress management program in which nursing students can efficiently manage and cope with their stress is urgently needed .

Stress management is one of the basic foundational strategies for maintaining one's health at any age, ensuing optimum learning and retention during training, successful in the academic setting, and preparing them for a successful transition to the work environment ${ }^{(1,7)}$. Moreover, nursing students must adopt successful stress reduction behaviors as part of a healthy lifestyle ${ }^{(\mathbf{1 9 )}}$.

Aim of the study was to :evaluate the efficacy of stress management program on the level of perceived stress and coping strategies among Baccalaureate Nursing Students.

\section{Research hypothesis:}

After implementing the stress management program the stress level and coping strategies among Baccalaureate Nursing Students expected to be improved

\section{Subject and method}

Research Design: A quasi-experimental with one group pre- test post -test design was utilized in the current study.

Setting: The study was conducted at faculty of nursing, Tanta University affiliated to the ministry of higher education.

Subjects: Subjects of the study were a convenience sampling of 100nursing students at academic year (2017-2018). The sample size was calculated using Epi-Info software statistical package created by World Health Organization 
and Center for Disease Control and Prevention, Atlanta, Georgia, USA version 2002. The criteria used for sample size calculation were as follows: $95 \%$ confidence limit. $80 \%$ power of the study, expected stress prevalence $75 \%$ to decrease after intervention to $55 \%$. The sample size should be $(\mathrm{N} \geq 90)$.

Criteria for nursing students' selection were: Fourth academic year nursing students of both sex and agree to participate in the current study.

\section{Tools of the study:}

\section{Tool I: Perceived stress scale (PSS):}

It was developed by Cohen et al $(1983)^{(20)}$. The scale composed of fourteen items and used to measure the degree to which situations in an individual's life are evaluated as stressful. It is the most frequently used instrument for measuring the perception of stress. Its items are of a general nature; therefore, it can be used with any population.

Scoring: All items were scored on a five-point likert scale coded from 0 (Never) to 4 (Very Often) except seven items $(4,5,6,7,9,10$, and 13) the score must be reversed. The total score of overall items was summed to determine the level of stress as the following: Low level of stress ranged from $(0-18)$, Moderate level of stress (19-37), and High level of stress (3856)

\section{Tool II:University student's stressors}

It was developed by the researchers based on reviewing the literature. It used to assess the sources of stressor that faced nursing students. It consisted of 71 items listed under nine categories namely academic(7items), Time/Balance (7items), Work (6items), Intrapersonal/Self(10items), interpersonal/social(7items), Family(5items),Teaching quality (11items), Financial (7 items), and environmental (11items). Respondents were asked to answer the questions on five-point likert scale ranging from 1 (not at all) to 5 (very much) for all these subscales, a mean scare was calculated and the higher the score the greater the level of the measured construct.

Tool III: Coping inventory of stressful situations (CISS):

It was developed by Endler and Parker $(1990)^{(21)}$. The scale used to measure multidimensional coping styles used when the individuals are faced with stressful or upsetting situations. It consisted of 48 items divided into three 
subscales ( 16 items in each ), that assess the three basic dimension of coping style namely task-oriented, emotion- oriented, and avoidanceoriented coping style.

Task-oriented coping subscale and described as a purposeful behaviors focused on solving a situation. The emotion-oriented coping subscale is aimed to reduce stress and maintain emotional equilibrium. The avoidanceoriented coping subscale is aimed to disengage cognitively or behaviorally from the stressful experiences by avowing stressors or one's reactions to it.

Respondents were asked to answer the questions on five point likert scale ranging from 1 (not at all) to 5 (very much ) for all these subscales, a mean scare was calculated and the higher the score the greater the level of the measured construct

\section{Method:}

1-Official permission was obtained before conducting this study from the dean of Faculty of Nursing, Tanta University.

\section{Ethical consideration:}

- Verbal consent was obtained from the study subjects after explanation of the purposes of the study

-Confidentiality were assured to the study subjects
-The study subjects had the right to withdrawn from this study at any time and this should be respected and assured -The study subjects were informed that their evaluation in the psychiatric course was not affected by the program applied in this study.

3-All tools were tested for content validity by a jury of five experts in the field of psychiatric nursing.

4-All tools of the study were tested for reliability and Cronbach alpha was used and found to be $0,794,0,957$, and 0,927respectively for tool I, II, and III which represent highly reliable tools.

5-Pilot study was carried out with 10 undergraduate nursing students to evaluate the tentatively tools for the clarity, feasibility and the applicability and necessary modifications were done accordingly. Those10 undergraduate nursing students were excluded later from the actual study.

6-Data collection for this study was extended for period of three months (from 1-11-2017 to 30-3-2018).Data was collected using self-administered questionnaire .

The study was conducted through the following phases

\section{1-Assessment phase:}

In this phase all nursing students were interviewed to explain the purpose of the 
study and to gain their cooperation. The researcher assigns the study tools on the students and explains how to fill the questioner .Time require to fill the questionnaire was lasted between 30 to 45 minutes

\section{2-Planning phase:}

This phase was formulated based on assessment phase and extensive literature review. Goals and expected outcome criteria were taking into consideration when planning stress management program.

The nursing students were divided into subgroups; each subgroup encompassed 15 students (8 students for each researcher). Each subgroup was attending a total of 6 sessions. These sessions were scheduled as 3 sessions per week for duration of 2 weeks. Each session was lasted for about two hours

\section{The researcher was used the following} learning strategies:

- Modeling: it was done with either the researcher or the study subjects in order to teach them how to practice stress management strategies.

- Getting participant's feedback (e.g.Providing corrective feedback).

of stress, factors affecting stress, adaptive and maladaptive coping strategies)
- $\quad$ Positive reinforcement (e.g. praising a student's efforts).

The researcher was used the following learning materials: $C D$ \& laptop. Videos

The program involved theoretical part, as well as practical part and homework assignments (such as exercise, listening to music, spiritual practices).

The intervention in the study was based primarily on a cognitive-behavioral orientation

\section{3-The implementation phase:}

- In this phase, the researchers were meet the study subjects in a quiet room, the seats will be arranged in a circular shape.

- The content of the program was presented in the following sequences:

\section{The first session:}

An introductory session that emphasized establishing rapport between the researchers and all students participating in the study and explanation of the purpose of the program

The second session :it includes education about stress and coping includes (definition of stress, theories of stress, signs and symptoms of stress, stressors and sources The third session; includes education about hardiness. hardiness education id 
defied as a comprehensive approach to managing stress that enable them to under stress to have a greater sense of control , feel committed, and to view change as a challenge .b- Self-care information such as proper sleep, proper nutrition, proper exercise, and proper recreation.

The fourth session: includes relaxation training (deep breathing exercise and progressive relaxation techniques)

The fifth session; includes cognitive techniques (stress awareness log, problem solving)

The sixth session; behavioral techniques includes (time management, guided imagery, learning assertive communication pattern)

Finally at session 7:summary of the program and the questionnaires were given to the subjects to complete them as an immediate evaluation of the program.

4-The evaluation phase: All students were evaluated after implementing the program by using tool I and III.

Statistical analysis: The collected data was organized, tabulated, coded and statistically analyzed using the mean, standard deviation standard error, unpaired student t-test, the linear correlation coefficient, Analysis of variance [ANOVA] tests Paired t-test and chisquare by SPSS V19 (Statistical Package for Social Studies) created by IBM, Illinois, Chicago, USA. The level of significance was adopted at $\mathrm{p}<0.05$.

Result: Table (1) presented the means and standard deviations of stressors as perceived by nursing students. It was observed that environmental stressor obtained the highest mean score $(18.27 \pm 5.19)$ followed by teaching quality/Relations with teachers/Support from teachers, academic, Intrapersonal/ Self, time, and relationships/Interpersonal/ Social and financial stressor. (16.37 \pm 4.75 , $14.70 \pm 5.46, \quad 12.71 \pm 3.87, \quad 12.71 \pm 2.92$, $10.06 \pm 4.77$, and $10.06 \pm 4.30$ respectively)

Table (2) revealed the distribution of the studied nursing students at pre and post intervention in relation to their perceived stress. It was noted that more than half of the studied students had high level of perceived stress $(55 \%)$, and quarter $(25 \%)$ of them had moderate level and 20\% had low level of stress at the pre -intervention phase while after implementing the intervention about one third of them had low level of stress $(30 \%)$, and more than half $(55 \%)$ of them had moderate level and only $15 \%$ of them had high level of stress. There was a statistical significant difference in the perceived stress at pre and post- intervention phases.I 
Figure (1) illustrated the means and standard deviations of coping strategies used by the studied nursing students at preintervention. It was observed that emotionfocused coping obtained the highest mean score of coping $(48.250 \pm 12.761)$, while the task-focused coping obtained the lowest mean score of coping $(35.940 \pm 11.172)$.

Table (3):showed the mean difference scores of perceived stress among nursing students at pre and post-intervention. It can be noticed that the mean score of the perceived stress decreased from 31.130 \pm 7.337 pre- intervention to 26.330 \pm 4.667 post- intervention with a highly statistically significant difference $(\mathrm{t}=6.125 \mathrm{p}=0.001)$

Table (4) showed the mean difference scores of coping strategies used by nursing students at pre and post-intervention. Regarding task oriented coping strategy, It can be noticed that the mean score of the task-oriented coping strategy increased from $35.940 \pm 11.172$ pre- intervention to $38.730 \pm 7.402$ post- intervention with a statistically significant difference $(\mathrm{t}=2.990$ $\mathrm{p}=0.004)$.On the other hand, the mean score of emotion- focused coping and avoidance-focuse dcoping decreased from $48.250 \pm 12.761$ pre- intervention to $43.180 \pm 12.654$ post intervention with a highly statistically significant difference $(\mathrm{t}=5.121 \mathrm{p}=0.001)$ and $44.130 \pm 10.766$ pre- intervention to41.970 \pm 12.523 post intervention with a highly statistically significant difference $(\mathrm{t}=3.503 \quad \mathrm{p}=0.001)$ respectively

Table (5) demonstrated the correlation between perceived stress and coping strategies used by nursing students at pre intervention. It appeared from this table that perceived stress was highly significantly negatively correlated with task-focused coping strategy ( $\mathrm{r}=-0.488$, $\mathrm{p}=0.001$ ). This means that the higher the degree of using task - oriented coping strategy, the lower level of perceived stress. While perceived stress was highly significantly positively correlated with emotion-focused coping and avoidancefocused coping $(r=0.756, p=0.001$ and $r=$ 0.544, $\mathrm{p}=0.001$ respectively). This means that the higher level of perceived stress, the higher the degree of using emotion-focused coping and avoidance-focused coping strategies. 
Table (1) Total means score of the studied nursing students in relation to their stressors

\begin{tabular}{|c|c|c|c|}
\hline \multirow{2}{*}{ Student's perceived stressors(n=100) } & \multicolumn{3}{|c|}{ Score } \\
\cline { 2 - 4 } & Mean & \pm & SD \\
\hline Academic & 14.70 & \pm & 5.46 \\
\hline Time/Balance & 12.71 & \pm & 2.92 \\
\hline Work & 7.73 & \pm & 3.46 \\
\hline Intrapersonal/Self & 12.71 & \pm & 3.87 \\
\hline Family & 6.90 & \pm & 3.47 \\
\hline Felationships/Interpersonal/Social & 10.06 & \pm & 4.77 \\
\hline Feaching quality & 16.37 & \pm & 4.75 \\
\hline Financial & 10.67 & \pm & 4.30 \\
\hline
\end{tabular}

Table (2)Distribution of the studied nursing students at pre and post intervention in relation to their perceived stress

\begin{tabular}{|c|c|c|c|c|c|}
\hline \multicolumn{2}{|c|}{$\begin{array}{c}\text { Levels of perceived } \\
\text { stress } \\
(\mathbf{n = 1 0 0})\end{array}$} & \multicolumn{2}{|c|}{ Items } & \multicolumn{2}{c|}{ Chi-square } \\
\cline { 2 - 4 } & Lre-intervention & Post-intervention & $\mathbf{X}^{\mathbf{2}}$ & P-value \\
\hline \multirow{3}{*}{ Low } & $\mathbf{N}$ & 20 & 30 & & \\
\cline { 2 - 4 } & $\%$ & $20 \%$ & $30 \%$ & & \\
\hline \multirow{3}{*}{ Moderate } & $\mathbf{N}$ & 25 & 55 & \multirow{2}{*}{0.001 ** } \\
\cline { 2 - 5 } & $\%$ & $25 \%$ & $55 \%$ & \\
\hline \multirow{2}{*}{ High } & $\mathbf{N}$ & 55 & 15 & & \\
\cline { 2 - 5 } & $\%$ & $55 \%$ & $15 \%$ & & \\
\hline
\end{tabular}

$* \mathbf{p}<\mathbf{0 . 0 5} \quad * * \mathbf{p}<0.001$




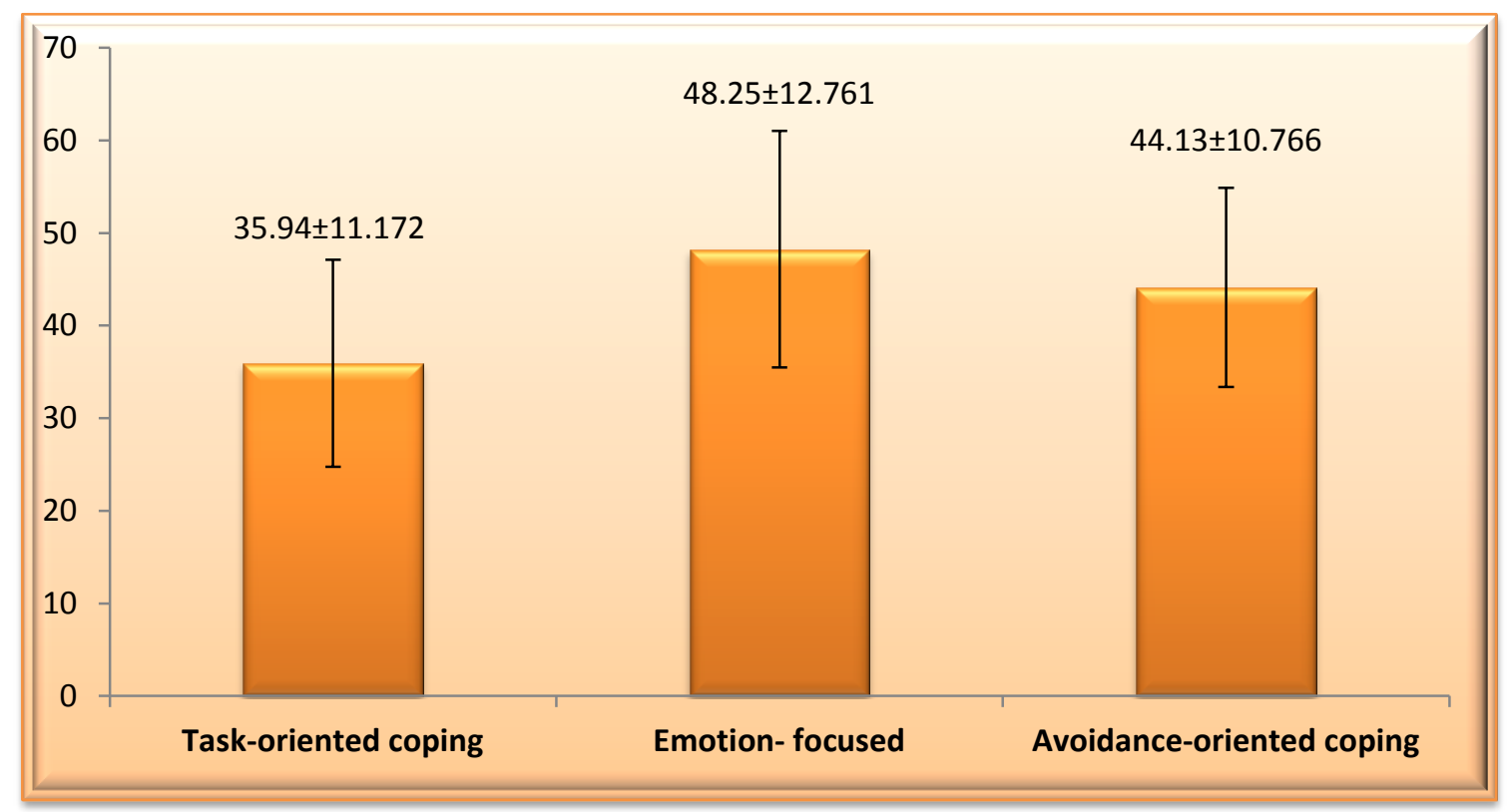

Figure 1: Means and standard deviations of coping strategies used by nursing students at pre-intervention.

Table (3) the mean difference scores of perceived stress among nursing students at pre and post-intervention.

\begin{tabular}{|c|c|c|c|c|c|c|c|}
\hline \multirow{2}{*}{$\begin{array}{c}\text { Phases of the } \\
\text { program }\end{array}$} & \multicolumn{3}{|c|}{$\begin{array}{c}\text { Perceived } \\
\operatorname{stress}(n=100)\end{array}$} & \multicolumn{2}{|c|}{ Mean difference } & \multicolumn{2}{|c|}{ Paired T-test } \\
\hline & Mean & \pm & SD & Mean & SD & $\mathbf{T}$ & P-value \\
\hline Pre-intervention & 31.130 & \pm & 7.337 & \multirow{2}{*}{4.800} & \multirow{2}{*}{7.837} & \multirow{2}{*}{6.125} & \multirow{2}{*}{$0.001 * *$} \\
\hline Post-intervention & 26.330 & \pm & 4.667 & & & & \\
\hline
\end{tabular}

$* \mathbf{p}<0.05$

$$
* * \mathbf{p}<0.001
$$


Table (4) the mean difference scores of coping strategies used by nursing students at pre and post-intervention

\begin{tabular}{|c|c|c|c|c|c|}
\hline \multirow{3}{*}{ Coping strategies } & \multicolumn{2}{|c|}{ Mean \pm SD } & \multirow[t]{3}{*}{$\begin{array}{c}\text { Mean } \\
\text { differences } \\
\text { Mean } \pm \text { SD }\end{array}$} & \multicolumn{2}{|c|}{ Paired T-test } \\
\hline & Pre-intervention & Post-intervention & & & \\
\hline & & & & $\mathbf{T}$ & P-value \\
\hline $\begin{array}{l}\text { Task-oriented } \\
\text { coping }\end{array}$ & $35.940 \pm 11.172$ & $38.730 \pm 7.402$ & $2.790 \pm 9.331$ & 2.990 & $0.004 *$ \\
\hline $\begin{array}{c}\text { Emotion- oriented } \\
\text { coping }\end{array}$ & $48.250 \pm 12.761$ & $43.180 \pm 12.654$ & $5.070 \pm 9.900$ & 5.121 & $0.001 * *$ \\
\hline $\begin{array}{c}\text { Avoidance- } \\
\text { oriented coping }\end{array}$ & $44.130 \pm ` 10.766$ & $41.970 \pm 12.523$ & $2.160 \pm 6.166$ & 3.503 & $0.001 * *$ \\
\hline
\end{tabular}

$* \mathbf{p}<\mathbf{0 . 0 5} \quad * * \mathbf{p}<0.001$

Table (5) correlation between perceived stress and coping strategies among nursing students at pre intervention

\begin{tabular}{|l|c|c|}
\hline \multirow{2}{*}{ Coping strategies } & $\begin{array}{r}\text { 'Total score of perceived } \\
\text { stress(n=100) }\end{array}$ & \multirow{2}{*}{ P } \\
\cline { 2 - 2 } & Pearson correlation test (r) & \\
\hline Task-focused coping & -0.488 & $0.001^{* *}$ \\
Emotion- focused coping & 0.756 & $0.001^{* *}$ \\
Avoidance-focused coping & 0.544 & $0.001^{* *}$ \\
\hline
\end{tabular}

$* \mathbf{p}<\mathbf{0 . 0 5} \quad * * \mathbf{p}<0.001$ 


\section{Discussion}

An undergraduate program in nursing is a period that creates stress and anxiety in the student since the course is considered difficult, demanding and highly competitive. The results of the present study revealed that more than half of the studied students had high level of perceived stress, and quarter of them had moderate level at pre-intervention phase. On the same direction with the present study results, two studies found that nursing students reported moderate to high levels of perceived stress ${ }^{(22,23)}$. Similarly, Alsaqri2017 found that more than half of the studied students had high level of perceived stress ${ }^{(24)}$. In contrary, a study conduct by Sharma and Kaur (2011) found that majority (97\%) of the subjects had moderate level of stress whereas $3 \%$ had severe stress ${ }^{(\mathbf{2 5})}$.Needless to say that higher level of stress may be attributed to many stressors perceived by nursing students and as supported by the finding of the present study. The environmental factors had the maximum contribution in causing stress followed by teaching quality factors, academic factors, then intrapersonal factors. While family factors had the least impact in causing stress. These findings could be explained by the following:
First, our faculty has two disconnected buildings and the students are mannered to go between the two buildings, in addition to Lack of facilities and poor quality of faculty buildings and equipment. Moreover, most students come from far places and must find somewhere to live (being placed in an unfamiliar environment), in addition transportation difficulties and there is no enough leisure time.

Second, In Egypt, the current education policy allows an increasing number of admitted college students. The performance and quality of teaching is severely compromised as a result of increasing number of students and incompatibility in the ratio between the students and staff $\left({ }^{26}\right)$.

Third, too many things required at the same time such as studying for exam , preparing assignments and writing clinical paper .Additionally nursing students must not only endure burdensome theoretical learning, but also experience clinical practice $^{(27)}$.

Finally, this can be also interpreted in terms of psychosocial variables such as marital status or cohabitation status (separation from the Parents) and the demand of making new social groups apart 
from academic pressures and clinical training .Moreover these future nurses are expecting financial hardships after graduation due to low salaries which might reflect on their future social and family life $^{(28)}$

This result was also consistent with a study conduct by Sharma and Kaur(2011)which revealed that the environmental factors were had the maximum contribution in causing stress followed by interpersonal factors and academic factors ${ }^{(25)}$. Moreover these findings are to some extent consistent with the findings of a study conducted by Timmins et al (2002) revealed five factors that emerged as sources of stress; firstly, academic stress factors, the second and third components concern teaching quality, and the latter involving the clinical experience and the last two components suggest that finance and death of patients are independent sources of stress ${ }^{(29)}$.The difference between studies regarding the level of stress and type of stressors may be related to country of origin. Supporting this explanation a study conduct by Labrague et al (2017) revealed that the degree of stress and the type of stressors among nursing students differ according to the country of origin ${ }^{(30)}$.

Concerning the coping strategies used by nursing students, it can be concluded that the studied nursing students relied on emotion-focused and avoidance -focused coping strategies more frequently than problem-focused coping to negotiate their stressful life situations. This was in line with the results of Silva et al (2015) revealed that the main used coping strategies were those based on emotion, escape or avoidance to the stressor agent $^{(31)}$. Similarly, Hirsch et al (2015) reported that the coping strategy most used by nursing students is escape ${ }^{(\mathbf{3 2}) \cdot}$ This may be interpreted that emotion focused coping can be both positive and negative and this depending on the situation. When the stressful situation is outside a person's control, or cannot be changed, and or when the person needs to accept reality the emotion focused coping mechanism works best. It works by avoiding negative emotional responses associated with stress such as anxiety, depression, and frustration and this is obvious in the case of the present study where environmental factors had the maximum contribution in causing stress ${ }^{(\mathbf{3 3})}$.Supporting this explanation a study conducted by Ryan $2013^{(\mathbf{3 4})}$

On the other side, emotional involvement with a stressful reality can lead to the use of distancing self from reality as defensive mechanisms, which are ineffective for resolving the stress. By disconnecting the 
self from the reality, the individual adjusts negatively to the situations being experienced, which in turn can lead to feelings of isolation and, and consequently to apathy and lack of motivation to perform academic activities ${ }^{(35)}$.

Generally, strategies that focuses on emotions, solves little, and is not effective in managing the stressor, While problem focused strategy are more adaptive and effective for dealing with stressful situations than emotion-focused or avoidance strategies as it involves actively planning or engaging in a specific behavior to overcome the problem causing distress ${ }^{(34)}$. This is supported by the finding of the present study that found a statistical significant negative correlation between perceived stress and problem focused strategy. This means the higher the degree of using problem- focused coping strategy, the lower level of perceived stress. In paralle lGibbons et al (2014) reported that nursing students who used coping strategies focused on resolving problems had lower means of stress compared to those who used strategies focusing on emotions ${ }^{(\mathbf{3 6})}$. On the other side, there was a statistical significant positive correlation between perceived stress and emotion focused and avoidant-focused strategy. This is consistent with a study found that
Emotion focused coping showed weak positive correlations with perceived stress (34). In this respect Reeve et al(2013) found that nursing students who used escapeavoidance strategies to cope with stress were those who attained the highest stress means in all of the domains ${ }^{(7)}$.

Concerning the effect of stress management program on the nursing student's level of perceived stress and coping strategies. The present study found that the program was effective in reducing stress level and improves coping strategies (significant decrease in the mean score of perceived stress, emotion-focused coping and avoidant-focused coping, and significant increase in the mean score of problem-focused coping). In this respect a study conducted by Chinaveh et al (2013) speculated that Students who received the MSMI had lower scores for avoidance responses and perceived stress ${ }^{(37)}$. Additionally,Kavianiet al(2007),found that Cognitive-behavioral coping strategies are the most effective methods to reduce the stress (38). Likewise Yazdaniet al (2010)when they compared mean scores of stress in the intervention group in three phases, before, after and one month after the intervention, results showed a significant difference which approved the 
efficacy of cognitive and behavioral stress management onreducing stress ${ }^{(39)}$.

These results may be attributed to the acquired competencies and skills developed during the implementation of the stress management training program itself, as the training program encompasses a wide array of variety techniques that includes relaxation, cognitive, and behavioral techniques all aimed at providing students with the opportunities to apply several exercises in face of stress. Presumably, by using these techniques, the level of stress decreased and coping strategies of the nursing students improved and hence it is reflected in their abilities to negotiate their stressful life situation.

Moreover the session that focused on hardiness education. Hardiness is defined as a personality characteristic that related to the ability to defense, offer resistance to, and cope with stressful situations as it includes components of commitment, control, and challenge. This is supported by a study found that; the hardiness intervention did have a statistically significant effect on decreasing perceived stress scores. Stress still exists in nursing education. Empowering nursing students with skills to increase their inherent hardiness and decrease their perceived stress is an imperative ${ }^{(\mathbf{4 0})}$.

\section{Conclusion}

Based on the findings of the present study, it can be concluded that the stress management program was effective in reducing stress level and improves coping strategies.

\section{Recommendation}

Based on the findings of the present study the following recommendation was suggested:

1- Create or activate psychological counseling unit in the faculty to help students adapt to stress and improve their mental health.

2- The role of the psychiatric nursing department should not be ignored, because they can have a valuable role in reducing the stress and facilitate the students learning.

3- Holding stress management workshops in different courses and implementing psychotherapy training programs can improve the mental health of the students.

\section{References}

1- CraryP. Beliefs, behaviors, and health of undergraduate nursing students. Holist Nursing Practice2013; 27 (2): 74-88

2- Loubir D\& Serhier Z, DiounyS, Battas O, Agoub M, and Othmani M. Prevalence of stress in Casablanca 
medical students: a cross-sectional study. African Medical Journal. 2014; 19 (149)

3- Harmelink A. pilot study of the effects of heart rate variability biofeedback on perceived stress, perceived coping ability ,and resilience in accelerated baccalaureate nursing students. ProQuest LLC. 2016

4- Basavanthappa B T. Fundamentals of nursing. Jaypee brother's medical publishers; New Delhi 2004.

5- Chernomas W \& Shapiro C. Stress, depression, and anxiety among undergraduate nursing students. International Journal of Nursing Education Scholarship 2013; 10: 255-266

6- Salamonson Y, Everett B, Koch J, Andrew S, Davidson P. The impact of term-time paid work on academic performance in nursing students: a longitudinal study. International Nursing J2012; 49 (5): 579-585

7- Reeve K, ShumakerC, YearwoodE, Crowell N, Riley J. Perceived stress and social support in undergraduate nursing students' educational experiences. Nurse Education Today 2013; 33 (4): 419-424.

8- GoffA. Stressors, academic performance, and learned resourcefulness in baccalaureate nursing students. International Nursing Educ. 2011.

9- Jeffreys M. Tracking students through program entry, progression, graduation, and licensure: assessing undergraduate nursing student retention and success. Nurse Education Today. 2007;27 (5), 406419

10- Zurilla D, Sheedy T.Relation between social problem-solving ability and subsequent level of psychological stress in college students. Journal of Personality and Social Psychology. 1991; 61(5): 841-846

11- Nadig N, Huff NG, and, Ford DW. Coping as a Multifaceted Construct: Associations with Psychological Outcomes among Family Members of Mechanical Ventilation Survivors. Crit Care Med. 2016 Sep;44(9):1710-7

12- Compas BE, Connor-Smith JK \& Saltzman H. Coping with Stress during Childhood and Adolescence: Problems, Progress, and Potential in Theory and Research. Psychological Bulletin 2001, Vol. 127, No. 1,87-127

13- FolkmanS, LazarusR S. An analysis is of coping in a middle-aged community sample. Journal of Health and Social Behavior,21,219-239. Quoted from: SundqvistJ 
,Ghazinour $M$, and Padyab $M$. Coping with Stress in the Forced Repatriation of Unaccompanied Asylum Seeking Refugee Children among Swedish Police Officers and Social Workers. Psychology, 2017, 8, 97-118.

14- Skinner. Coping assessment.2006 Available at http://pdx.edulsiteslwww .pdx.edu....pdf. Retrieved on 2014

15- Folkman S. The case for positive emotions in the stress process. Anxiety Stress Coping. 2007; 21:3-14. doi: 10.1080/10615800701740457.

16- Al Zayyat A \& Al Gamal E. Perceived stress and coping strategies among Jordanian nursing students during clinical practice in psychiatricmental health courses. Int. J. Mental Health Nursing. 2014;23(4):326-35.

\section{7- Ranade A, Kulkarni G and} Dhanumali S. Stress study in 1st year medical students. International Journal of Biomedical and Advance Research. 2015; 6(06): 499-503.

18- Sreeramreddy CT, Shankar PR, Binu VS, Mukhopadhyay C, Ray B. Psychological morbidity, sources of stress and coping strategies among undergraduate medical students of Nepal. BMC Medical Education 2007; 7(26).
19- Kadda O. Emotional intelligence on nursing as an anxiety management tool. Health Science Journal. 2014; 8 (2): $152-153$

20- Cohen S, Kamarck T, and Mermelstein R.A global measure of perceived stress. Journal of Health and Social Behavior 1983; 24: 385-396

21- Endler NS, Parker JD .Assessment of multidimensional coping: task, emotion, and avoidance strategies. Psychologicalassessment1994;6(1):50-60

22- Bhandari P.Stress and health related quality of life of Nepalese students studying in South Korea:A cross sectional study. Health and Quality of Life Outcomes. $2012 ; 10$ : 1-9

23- Eswi A, Radi $\mathbf{S}$ and Youssri $H$. Stress/ Stressors as Perceived by Baccalaureate Saudi Nursing Students. Middle-East Journal of Scientific Research. 2013;14 (2): 193-202.

24- Alsaqri S. Stressors and Coping Strategies of the Saudi Nursing Students in the Clinical Training: A Cross-Sectional Study. Education Research International Volume 2017 (2017), Article ID 4018470, 8 pages

25- Sharma N, Kaur A. Factors associated with stress among nursing students. Nursing and Midwifery 
Research Journal.2011; 7(1)

26- Moustafa A. The axes of the future dimension of the development of university education in Egypt to face the unemployment of graduates. Journal of Financial and Commercial Studies. 2004; 2 (12) :213-220

27- Kang Y, Choi S, Ryu E. The effectiveness of a stress coping program based on mindfulness meditation on the stress, anxiety, and depression experienced by nursing students in Korea. Nurse Education Today. 2009;29 : 538-543

28- Theresa R. Implication for advancement of Egyptian Nursing: input equal output. White paper for Fulbright Academy. Workshop in Doha, March 23-25, 2007.

29- Timmins F,Kaliszer M. Aspects of nurse education programmes that frequently cause stress to nursing students - fact-finding sample survey. Nurse Education Today. 2002; 23(2):203-211

30- Labrague LJ, McEnroe-Petitte DM, Papathanasiou IV, Edet OB, Tsaras K, Leocadio MC, Colet P, Kleisiaris CF, Fradelos EC, Rosales RA, Vera Santos-Lucas K, and Velacaria PIT. Stress and coping strategies among nursing students: an international study. Mental Health J. 2017; 12 (20):1-7.

31- Silva T, Barros PH, Pinto $M$, Lacerda Sh , Medeiros A , Figueiredo T. Coping strategies used by student of the graduate nursing program Journal of Nursing. 2015;9 (9):9937-44.

32- Hirsch CD, Barlem ELD, Almeida LK, Tomaschewski-Barlem JG, Figueira AB, and Lunardi VL. Coping strategies of nursing students for dealing with university stress. Rev Bras Enferm. 2015;68(5):501-8

33- Stress Management : Emotion Focused and Problem Focused Coping Strategies. January 6, 2016. Available at:http://www.unstressyourself.com/e motion-focused-problem-focusedcoping-strategies/. Retrieved on march2018

34- Ryan K. How problem focused and emotion focused coping affects college students' perceived stress and life satisfaction. DBS School of Arts, Dublin. 2013

35- Monteiro C, Freitas J, Ribeiro A. Stress in the Academic Daily: A Nursing Student View from the Federal University of Piaui - Brazil. Escola Anna Nery. 2007 ;11(1):66-72. 


\section{6- Gibbons C, Dempster M,and}

Moutray M. Stress, coping and

37- satisfaction in nursing students. Advanced NursingJ.2011;67 (3):621-32.

38- Chinaveh M. The Effectiveness of Multiple Stress Management Intervention on the Level of Stress, and Coping Responses among Iranian Students. Procedia - Social and Behavioral Sciences. 2013 ; 84: 593 - 600

39- Kaviani H, Pournaseh M, Sayadlou S, Mohammadi MR. Effectiveness of stress management training in reducing anxiety and depression, participants in class exam. New Journal of Cognitive Sciences. 2007; 8(2): 61-8.

40- YazdaniM ,Rezaei S, Pahlavanzadeh S. The effectiveness of stress management training program on depression, anxiety and stress of the nursing students. IJNMR. 2010; 15(4): 208-215.

41- Jameson P. The effects of a hardiness educational intervention on hardiness and perceived stress of junior baccalaureate nursing students. Nurse Education Today.2014; 34(4):603. 